\title{
A Model of High School Student Financial Assistance System in China
}

\author{
Hua Ding, Zhongliang Guan and Zhihong Tian \\ 10113130@bjtu.edu.cn \\ Beijing Jiaotong University, China
}

\begin{abstract}
This paper puts forward an analytical model of ordinary high school student financial assistance system, based on the Dworkin theory and management of operational research. The model is constituted by constraint conditions, actors, model parameters and target parameters. Specific contents of each part are provided, and detailed analysis is carried out. Then, a case study is conducted to show how to apply the above model to analyze the assistance policy of high school student financial. The model could bring the work of high school student financial assistance to the height of the management science. This paper is of great significance to promote the development and popularization of high school education.
\end{abstract}

Keywords: Student financial assistance, high school education, subsidize mode, Ronald Dworkin

\section{Introduction}

We must have a clear and correct understanding about the issue of educational equity, for it is a fundamental problem of China's education. Educational equity includes the equity of education rights, education opportunities and education result. Education equity is an extension of social equity. High school education which is special and important connects compulsory education and higher education. Popularity of high school education is an important way of human resources investment and achievement of educational equity and social justice. However, relative to compulsory education and higher education, the theoretical research, policy development and implementation of high school student financial assistance are all insufficient. Therefore, in recent years, the development of high school education should be get much more attention.

"National medium and long-term plan for education reform and development (2010-2020)" puts forward that high school education is a key period to the students to form independent personality, and is significant to the improving the populace's cultivation and cultivating innovative talents. The development task of high school education is "popularizing high school education, improving ordinary high school students' comprehensive quality and promoting the diversified development of high school ". Since 2010 fall semester, our country establishes a policy system of high school student financial assistance.

Theoretical researches about funding for poor students include education fairness theory and public goods theory. Chu, et al., (2008) discuss the different policy implications of the three education fair principles - equality, difference and compensation. However, the paper does not analyze the practical circumstances in our country from the perspective of philosophy. Feng (2006) demonstrates poor students' education should belong to the category of public products and services from the angle of the functions of the government and the public finances. Li (2007) counts the enrollment of ordinary universities, ordinary high schools and ordinary junior high schools from 1990 to 2004 in our country, and points out that the ordinary high school education is the "bottleneck" 
restricting the development of the whole education. At the same time, he analyses the cost of education and living of rural children. $\mathrm{Hu}$, et al., (2001) put forward that the popularization 12 years education should be the new goal of national education development and imagine it. They also analyzes the abroad experiences and favorable conditions of the popularization of our country's 12 years education. The country could increase the fiscal transfer payment to poor areas, or increase financial aid to these areas.

Different countries have different funding policy and ways to ordinary high schools. In Algeria, Jordan, Burundi, all levels of education are free, and schools provide free meals to boarding students. Australia and Brazil take the way of life grants. Bangladesh takes the way of scholarship system. France, Japan, Thailand, India, Luxembourg adopts the system of loans, and Japan's national grants depend entirely on national student loans. The patterns of other countries' policy and ways have certain references value and instructive to our country.

Through a lot of literature research, we found that most literatures put forward suggestions to specific contents of funding system. However, the depths of literatures are not enough. At the same time, in the process of the policy system establishment, all sorts of practical problems will be encountered, for example, the regional differences, the complex relationship between education and economic or social development levels, and system operation and management, and so on. Combining the situation of education in our country, and the national education development planning, this paper puts forward an analytical model based on the Dworkin theory and management of operational research. The model could bring the work of high school student financial assistance to the height of the management science. This paper is of great significance to promote the development and popularization of high school education. After build the model, a case study is conducted to show how to apply the above model to analyze the assistance policy of high school student financial.

\section{Basic Theory}

\subsection{Theory of Dworkin}

Theory of John Rawls is popular among Chinese scholars in the study of education equity. In fact, in addition to Rawls, Nozick and Dworkin (2002) also put forward related theories. They all belong to the liberalism genre and argue equal rights. However, they have different understandings about the distribution of the resources.

Rawls $(1971,2001)$ pursues equal justice, and he proposes the difference principle, and tries to achieve fairness by the unequal distribution. Rawls pursues the equality principle of results, and his theory is not suitable for high school education. On the one hand, the high school education is not popular or compulsory education, it is not necessary distributed equally to all people. On the other hand, there are selections and recruitment in high school education which is a kind of elitist education, and the best education resources should be given to the best performers. Hence, Rawls's theory is suitable for compulsory education.

Nozick (1974) pursues "justice in holdings". He thinks that only personal deserve is justice. The sufficient and necessary condition of justice in holdings is the both justice of acquirement and transfer. Nozick's theory is suitable for higher education. Higher education belongs to the elite education in nature, and it insists that the more outstanding, the better education receive.

Rawls and Nozick are two extremes of "equality" and "freedom" of liberal justice theory, and Dworkin is on the third way between them. In spite of the high school education belongs to basic education, it is by no means the extension of compulsory education. Because the other end of it is connected to the higher education. High school education should not only consider fair equality, but also pay attention to the freedom to 
choose. For the special mission and position, "resource equality" of Dworkin's theory is suitable for high school education. The development of individual and gain of resources depend on the ambition and choice of individual. According to Dworkin's theory, we need both public education and free choice and development to people.

\subsection{Operational Research Model}

Operational research (OR) encompasses a wide range of problem-solving techniques and methods applied in the pursuit of improved decision-making and efficiency, such as simulation, mathematical optimization, queuing theory and other stochastic-process models, Markov decision processes, econometric methods, data envelopment analysis, neural networks, expert systems, decision analysis, and the analytic hierarchy process. Management science is concerned with developing and applying models and concepts that may prove useful in helping to illuminate management issues and solve managerial problems, as well as designing and developing new and better models of organizational excellence. Management operational research is a subject based on operational research, and obtains optimization scheme of economic system in view of the real quantitative data to provide scientific operation decision of the system to decision makers.

There are four stages in application of operations research.

(1) Set goals and clear the problem. Including decompose the whole problem into sub problems, determine the validity, measurement, controllable and uncontrollable variables, and the scale of the problem, and constants and parameters representing relationships between variables. At present, there are two indicators to measure the level of high school education popularization in our country - the ratio of gross enrollment and the student number of dropping out of school. In addition to the longitudinal comparison inside the region, horizontal comparison with other areas should also be done by narrowing the difference of regional development. In addition, more innovative target parameters can be introduced for reference, such as proportion of admission to the university.

(2) Collect the data and model, including defining relationship, experience relationship, and standardize relationship. The important relationship of our model is the influence of constraint conditions on the financial assistance pattern. Constraint conditions include national macroscopic education policy and financial support, the district education financial support, regional economic and social development, regional development level of high school education, and family factors.

(3) Solve the model and optimize solutions. To solve the model is a process to design a student financial assistance model which is suitable for local actual situation under the specific constraints.

(4) Test model and optimization, including the application of the solution to solve practical problems. And find new problems in the process of plan implementation.

A typical operational research planning issues includes three parts: the decision variables, the objective function and the constraints. In the model of high school student financial assistance system, the decision variables include actors and assistance independent variables - subsidize scope, subsidize ratio, subsidize standard, subsidize form and capital share, and so on. The objective functions contains several goals parameters-improve the gross enrollment ratio, reduce the number of dropouts due to poverty and reduce the regional difference of education resources. The constraints are including characteristics of high school education, political institutional environment, the economic environment, the education resources environment, social and cultural environment, and the family environment. The mathematical expressions are as follows. There are $n$ goal functions composing the total goal, and there are $m$ constraint functions. $\boldsymbol{X}$ is the decision variable including $j$ branch variables. 


$$
\begin{aligned}
& \text { Goal }: Z=F\left(f_{1}(x), f_{2}(x), \ldots, f_{n}(x)\right) \\
& x=\left[x_{1}, x_{2}, \ldots, x_{j}\right] \\
& \text { s.t. } \\
& g_{1}(x)>0 \\
& g_{2}(x)>0 \\
& \ldots \\
& g_{m}(x)>0
\end{aligned}
$$

\section{The Model of Ordinary High School Student Financial Assistance System}

\subsection{Composition Analysis of Financial Assistance System}

At first, the composition of financial assistance system and internal relations should be analyzed. The nature of the high school student financial assistance system is to consider the reasonable allocation of limited funds, manpower and other resources, to obtain the highest efficiency, and to match funding principles and objectives. Hence, the core of financial assistance system is the "resource allocation". According to the ideas of operational research, when scientific decisions are designed, objectives and constraints must be considered. A few questions should be answered "Who provide the financial assistance? The local government? Other social organizations and individuals?" "Who should accept the assistance?" "How to select students?" and "How to fund them? By student jobs or other ways?"

The composition of financial assistance system is shown as Figure 1, constituted by the constraint conditions, target, actors, allocation, input and output. The dashed box reflects the assistance system with the input "subsidize capital" impacted by "capital share", "subsidize ratio" and "subsidize standard", and output "subsidize effect". In order to evaluate whether the fund allocation is reasonable and effective, a feedback loop between the target and subsidize effect must be established. If the subsidize effect is consistent with the target, the whole system is reasonable and effective. At the same time, in order to evaluate the efficiency of fund allocation, an input - output analysis is conducted. The Figure 2 shows the model of ordinary high school student financial assistance system.

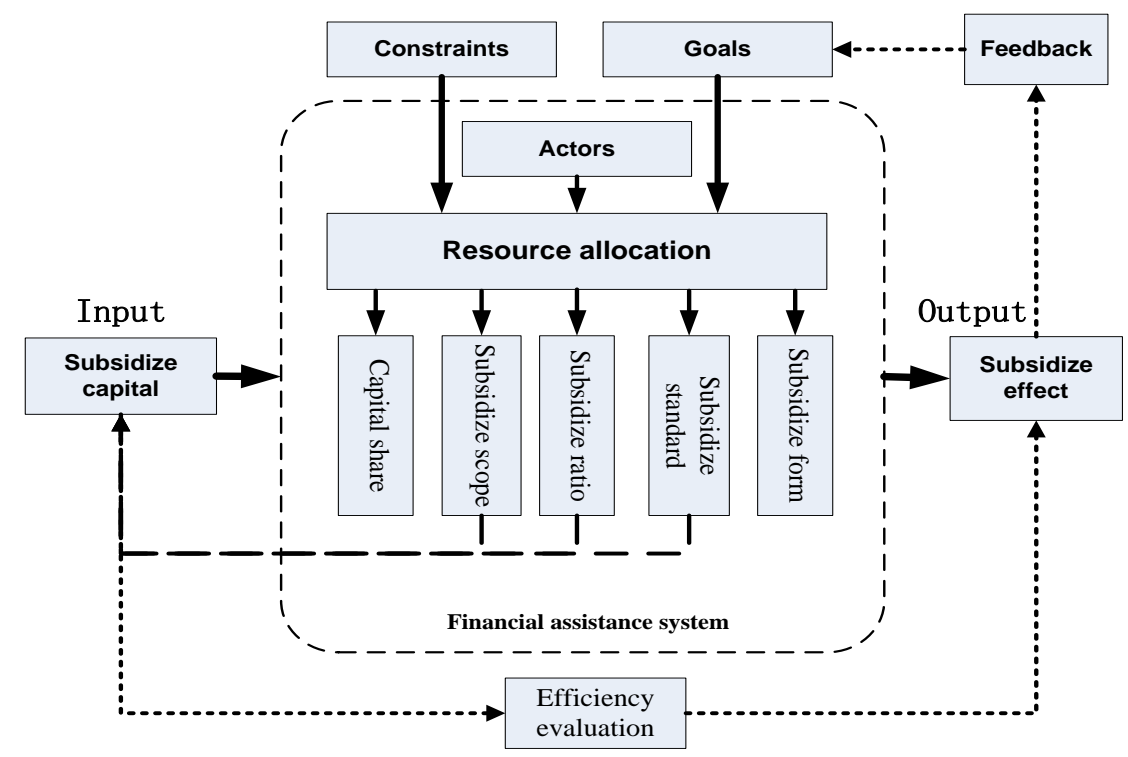

Figure 1. The Composition of Financial Assistance System 

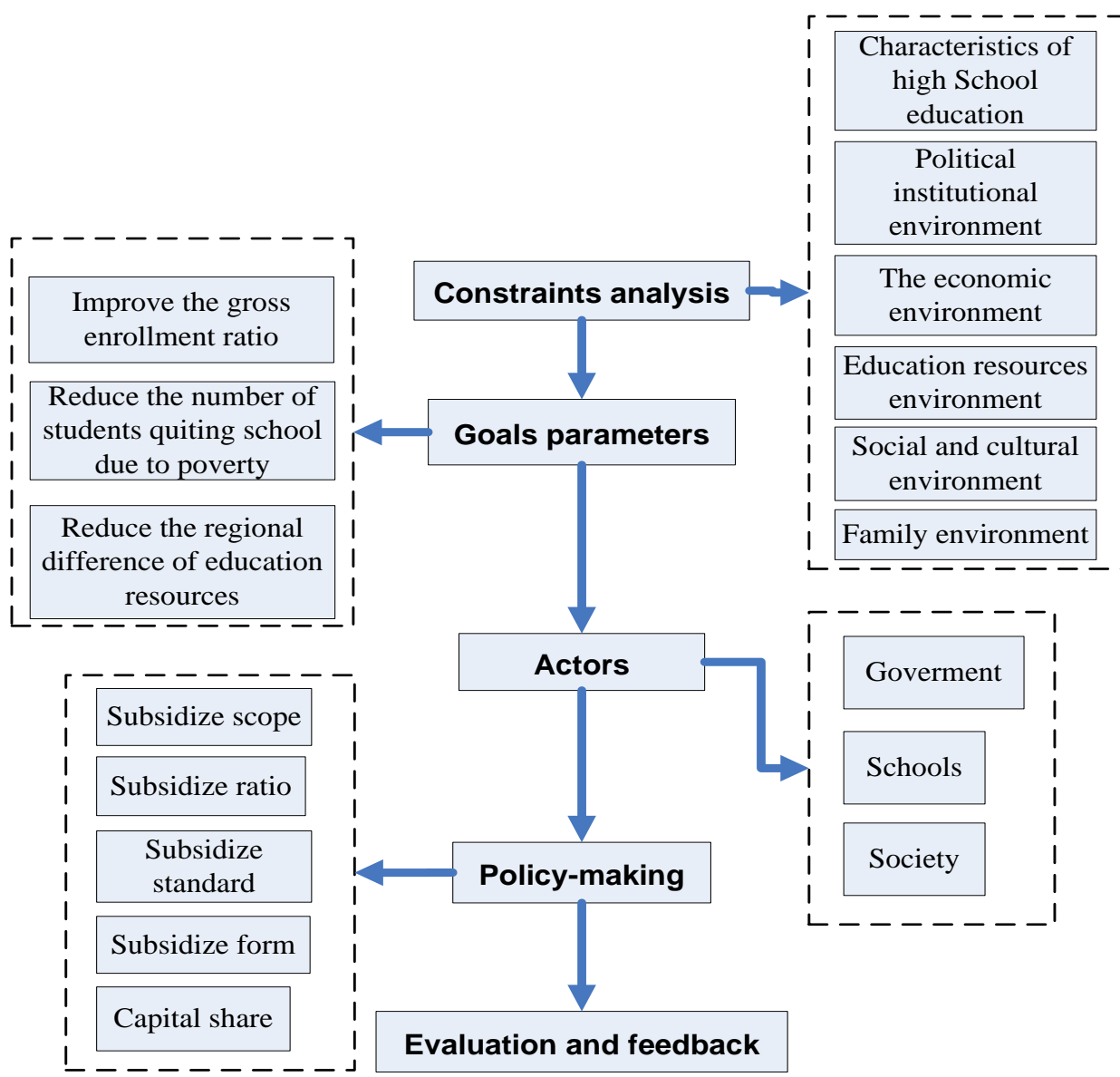

Figure 2. The Model of Ordinary High School Student Financial Assistance System

\subsection{Goals Parameters Analysis}

(1) Improve the gross enrollment ratio

The gross enrollment ratio which is an important index to measure the level of education development refers to a percentage of students in school of school-age population in certain school year and certain phase. It marks education relative size and education opportunities.

Enrollment is divided into two kinds: "the gross enrollment ratio" and "the net enrollment ratio". The gross enrollment ratio does not mean "roughly", but refers to regardless of the student's age in the gross enrollment ratio formula. "The net enrollment ratio" means that the formula includes only 15-18 years old students, without younger than 15 years old or older than 18 years old students. Unable to accurately know students' age distribution in future, so only "the gross enrollment ratio" can be used when government designs the development goals of the high school. The calculation method of provinces (autonomous regions and municipalities directly under the central government) high school gross enrollment ratio:

$$
\text { High school gross enrollment ratio }=\frac{\text { High school enrollment } \mathrm{s} \text { in one academic year }}{\text { The ethnic population }(15 \text { to } 18 \text { years old })} \times 100 \%
$$

"National medium and long-term plan for education reform and development (2010-2020)" puts forward the goals of high school: by 2020, high school education is popularized, and the gross enrollment ratio reaches $90 \%$. 
(2) Reduce the number of dropouts

Dropout means that a person who stops going to a school, college, etc., before finishing his stipulated academic. According to a survey, unequal education opportunity and the disadvantages of the institutionalized education are the root cause of dropouts.

\subsection{Constraints Analysis}

(1) The economic environment

Since 1997, the regional economic growth pattern in China appears new characteristics. The eastern coastal areas development advantages are more obvious. The eastern areas accelerate the process of connection with international standards, for the original relatively reasonable industrial structure, lower proportion of state-owned enterprises, and smooth industrial structure adjustment process. Meanwhile, the speed of adjustment of the industrial structure in Midwest areas is slow, due to the strong constraint "path dependence" of ownership structure and industrial structure. Under the condition of both the lack of external impetus and domestic demand, Midwest areas heavily depend on the state economy development, which is low efficiency, and hindering the economic potential. In Midwest areas, consumption growth is affected by the lack of income growth, and income growth is affected by the employment pressure.

In our country, economy in eastern is more developed than that in western region, coastal region is more developed than that in central parts, and city is more developed than that in countryside. Due to the unbalanced regional economic development, regional education resource configuration is also different. In particular, the government does not adopt effective measures to resolve the misallocation of high school education resource. Poor high school students in China are mainly distributed in economically underdeveloped, west areas, and the government should take additional compensation mechanism in less developed areas and poor areas.

\section{(2) Education resources environment}

After the founding of new China, the city-countryside dual structure and highly centralized resource allocation model are contributed to achieve the grand goal of modernization of the country. The main function of rural is accumulation of capital for urban. The city-countryside dual structure is the main factor of expanding the regional education gap between urban and rural. There are obvious gaps between urban and rural high school education in resource configuration. Since China's reform and opening up, in order to let some people become prosperous first, special economic zone has been established in the coastal in China. Government has given preferential policies to the special economic zone, such as investment, generation, taxes, etc., With the rapid economic development, education is also developing. Poor students in high school are out of sight, and parents and students are just more struggle for famous universities. However, in middle and western parts of China, due to the limitations of the geographical position and natural resources, economic development is backward. Compared with special economic zone and eastern region, the difference of high school education and economy are not comparable.

\section{(3) Family environment}

High school poor students' family are very poor, whose parents are often farmers, urban laid-off workers and Unemployed. Some ones need to pay medical expenses for a long time for serious illness of family members. Some ones suffer a sudden accident so that they cannot afford the student's high school education and living expenses. In addition, the single parent family or orphan is a major cause of poor students. Underdeveloped productivity and backward ideas of some poor areas make family have too many children and too heavy burden. All in all, the income and economic condition of 
poor family are very low, and they are members of social vulnerable groups.

\subsection{The Analysis of Independent Variables}

\section{(1) Subsidize scope}

When financial assistance system for poor high school students is established, rural and urban poor students should be all included in the scope. At present, funding for ordinary high school students is mainly in cities that are economically developed. However, in rural areas where more poor students are in, subsidize scope and the amount of funding are both limited, due to the pressure of funds. Our country is an agricultural country, and rural population accounts for $80 \%$ of the total population. There is big gap between urban and rural economic development. In the case of limited national energy, the government should ensure that poor ordinary high school students in Midwest backward rural areas don't drop out of school due to poverty.

(2) Capital share

Due to the ambiguity of policy, funding has been not carried out effectively across the country. At present, the provincial government subsidizes poor high school students in the form of grants. The specific allocation proportion is decided on their own by provinces and cities. Due to lack of financial support of the central government, economically backward provinces are unable to solve the problem of funding for all poor students.

One of the basic characteristics of funding work is that there is a large contrast of economic conditions and funding task in different areas. The better economic conditions of a place, the less the number of poor students, the more money; the poorer economic condition of a place, the more the number of poor students, the less money. To solve this contradiction, financial resources should be regulated and controlled by the central and provincial government. For example, according to the current financial management system of Guangxi, and considering financial situation, the autonomous region and municipal government share the capital and counties do not undertake any money. Hainan provincial high schools are burdened by the provincial fiscal. Haikou, Sanya, Yangpu economic development zone burden the money on its own. In other cities and counties, the province and cities share in accordance with the ratio 7:3.

\section{(3) Subsidize form}

Subsidize form can be roughly divided into two kinds: one is the awarding grant, which focuses on supporting those excellent students; the other one is subsidized grant, which mainly helps students with poor families. The current student subsidize form are: scholarships, grants, work-study programs, most needy aid, tuition waiver, student loans and other several forms. Grants, most needy aid and tuition waiver are suitable for ordinary high school students. At the same time the government can try to provide education loan to students.

\section{(4) Subsidize ratio}

Due to unbalanced economic development, the numbers of poor students in ordinary high schools are different. In general, the number of poor students in rural is higher than that in urban, and the number of poor students in developed regions is higher than that in backward area. According to the comprehensive measure, the proportion of ordinary poor high school students is from $15 \%$ to $20 \%$. Among them, the proportion of particularly poor students is around $10 \%$. The current practice subsidize ratio is generally $8 \%$ of all students. Subsidize ratio of ordinary high school in our country is relatively narrow. Many families basically have no economy source, and can not provide any fees for schools. Pressure on the economy has affected poor students' study and living, and even some students quit school due to family economic pressure. The proportion of poor students in 
each region can be measured according to the specific local standard.

\section{Case Study}

\subsection{Background}

In this section, a case study is conducted to show how to apply the above model to analyze the assistance policy of high school student financial. The case is the $\mathrm{N}$ county of the $\mathrm{M}$ province in China. Due to its western location in China, the economy and traffic of $\mathrm{M}$ province are not developed. M province includes about eighty counties (cities) and a population of about twenty million. In 2012, the number of ordinary high school students is 430000 , including 170000 poverty students. The average enrollment rate is about $70 \%$, which is relatively low in China. There are a variety of reasons: First, a large number of junior middle school graduates cannot accept the ordinary high school education due to tuition fees; Second, many ordinary high school freshman dropout due to tuition fees, and so on. The policies of $M$ province are as follows: (1) Subsidize scope and ratio: The subsidize scope of the poorest parts is $100 \%$, and that of other parts is $30 \%$. (2) Capital share: The central government and the local government share in accordance with the ratio $8: 2$.

\subsection{Subsidize Efficiency Research}

In order to analyze the subsidize efficiency of $\mathrm{N}$ county, enrollment rate is adopted as the objective indicator, and the production function model is $Y=f(K, L)$. In the equation, $Y$ reflects enrollment rate and $K$ reflects subsidize capital, and $L$ reflects other education input. Ignore $L$, the regression model is as follows:

$$
Y=\alpha+\beta K+\mu_{t}
$$

Data of the case is the subsidize capital and enrollment rates of N County from 2003 to 2012, as Table 1.

Table 1. Subsidize Capital and Enrollment Rates of N County from 2003 to 2012

\begin{tabular}{|l|l|l|}
\hline Year & $\begin{array}{l}\text { Subsidize } \\
\text { capital }\end{array}$ & Enrollment rate \\
\hline 2003 & 0.5 & 0.32 \\
\hline 2004 & 0.5 & 0.36 \\
\hline 2005 & 0.5 & 0.394 \\
\hline 2006 & 0.5 & 0.415 \\
\hline 2007 & 1.65 & 0.45 \\
\hline 2008 & 3.29 & 0.502 \\
\hline 2009 & 35.78 & 0.559 \\
\hline 2010 & 159.56 & 0.609 \\
\hline 2011 & 204.63 & 0.644 \\
\hline 2012 & 257.3 & 0.68 \\
\hline
\end{tabular}

(1) Unit root test ADF

Unit root tests of all series are conducted by Eviews. $z z$ reflects subsidize capital; $r x$ reflects enrollment rate. The test results show that $z z$ and $r x$ are all stationary, as Table 2 . 
Table 2. Unit Root Test ADF of All Series

\begin{tabular}{|l|l|l|l|l|l|}
\hline Variable & Statistic ADF & $1 \%$ level & $5 \%$ level & $10 \%$ level & Result \\
\hline zz & -1.333743 & -5.521860 & -4.107833 & -3.515047 & Non-stationary \\
\hline $\begin{array}{l}\text { 2nd } \\
\text { difference of } \\
\text { zz }\end{array}$ & -4.018894 & -7.006336 & -4.773194 & -3.877714 & Stationary \\
\hline rx & & & & & \\
\hline
\end{tabular}

(2) Co-integration test

In order to analyze whether there is co-integration relationship between subsidize capital $(z z)$ and enrollment rates $(r x)$, regression of the two series is conducted first, and then the stability of regression residuals is tested. The regression model is as follows:

$$
r x_{t}=0.417273+0.001351 z z_{t}+\hat{\mu}_{t}
$$

Then, the stability of regression residuals is tested without constant and time trend. The result is as Table 3 .

Table 3. Unit Root Test ADF of Residual

\begin{tabular}{|l|l|l|l|l|}
\hline Statistic ADF & $1 \%$ level & $5 \%$ level & $10 \%$ level & Result \\
\hline-2.183345 & -2.847250 & -1.988198 & -1.600140 & Stationary \\
\hline
\end{tabular}

Under the significance of 5\% level, statistic- $t$ is -1.988198 , which is bigger than corresponding critical value, hence hypothesis $H_{0}$ should be rejected. The result shows that regression residual is stationary, which implies that there is co-integration relationship between subsidize capital and enrollment rates.

(3) Error correction model

The co-integration relationship reflects that there is a long-term equilibrium relationship between subsidize capital and enrollment rates. However, in the short term, there may be unbalanced. In order to enhance the precision of the model, error term $\hat{u}_{t}$ could be seemed as equilibrium error, and an error correction model is established from regression equation (2) as following.

$$
\Delta r x_{t}=\alpha+\beta \Delta z z_{t}+\gamma \bar{\mu}_{t-1}+\varepsilon_{t}
$$

Make differences of $z z$ and $r x$ and get new series $d z z$ and $d r x$.

$$
\begin{aligned}
& d z z_{t}=\Delta z z_{t}=z z_{t}-z z_{t-1} \\
& d r x_{t}=\Delta r x_{t}=r x_{t}-r x_{t-1}
\end{aligned}
$$

$d r x_{\mathrm{t}}$ is the independent variable and $d z z_{t}$ and $\hat{\mu}_{t-1}$ are the dependent variables, and the regression results of error correction model is as Table 4.

Table 4. Regression Results of Error Correction Model

\begin{tabular}{|l|l|l|l|}
\hline$\alpha$ & $\beta$ & $\gamma$ & Durbin-Watson stat \\
\hline 0.040078 & $-6.51 \mathrm{E}-06$ & 0.121166 & 1.365137 \\
$(9.584355)$ & $(-0.053926)$ & $(1.511996)$ & \\
\hline
\end{tabular}

The test shows that, short-term dynamic relationship between subsidize capital and enrollment rates is positive, but not obvious. 


\section{Conclusion}

The case study shows that there is a stable equilibrium relationship between subsidize capital and enrollment rates, and the coefficient is 0.001351 . In long-term, there is a dynamic positive relationship between subsidize capital and enrollment rates, but not obvious. The output efficiency of subsidize capital is low. According to model in Figure 1 and 2, some suggestions are provided.

(1) Adjust the target group. Besides enrollment, more other goals could be considered.

(2) Adjust allocation ways. For example, expand social funding channels, and so on.

(3) Complete feedback channels. Establish perfect information collection and release system to provide accurate data to support evaluation and policy making.

Combining the situation of education in our country, and the national education development planning, this paper puts forward an analytical model based on the Dworkin theory and management of operational research. The model could bring the work of high school student financial assistance to the height of the management science. This paper is of great significance to promote the development and popularization of high school education. In future, after building the model, we should also further analyze the operation process of the model, which is the policy making process and the basis for assistance system.

\section{Reference}

[1] C. Hongqi and Y. Haiyan, "The principle of fairness of education and its policy implications", Educational research, vol. 336, (2008), pp. 10-16.

[2] F. Li and Y. Yinfeng, "Finance should become the leading role of national student loan", China's financial information, vol. 35, (2006), pp. 14-20.

[3] F. Jianjun, "Three Different Viewpoints of Educational Equity Comparison on educational equity viewpoints of J. RawIs, R. Nozick and R. Dworkiin", Comparative Education Review, vol. 28, no. 10, (2007), pp. 36-40.

[4] H. G. Unger, "Encyclopedia of American Education", Facts on File, Inc. New York, vol. 2, (1996).

[5] H. Angang and X. Yizhi, "Establish new education developing goals: popularization of 12 years education", Education research, (2001).

[6] L. Yaoqing, "Analysis of the Supply and Need of the Senior Middle School Education in the Rural Areas", Journal of Inner Mongolia normal university (educational science), vol. 20, no. 10, (2007).

[7] J. Rawls, "A Theory of Justice", London: Oxford University Press, (1971).

[8] J. Rawls, "Justice as Fairness: A Restatement", Harvard University Press, (2001).

[9] R. Nozick, "Anarchy, State, and Utopia”, New York: Basic Books, (1974).

[10] R. Dworkin, "Sovereign Virtue: The Theory and Practice of Equality", Harvard University Press, (2002).

[11] E. P. Bettinger, B. T. Long, P. Oreopoulos and L. Sanbonmatsu, "The Role of Application Assistance and Information in College Decisions: Results from the H\&R Block Fafsa Experiment*”, The Quarterly Journal of Economics, vol. 127, no. 3, (2012), pp. 1205-1242. 